\title{
Evaluation of Ultrasonication and Agitation Extraction Methods at Different Conditions on the Phenolic Composition and Antioxidant Activities of Mammillaria prolifera
}

\author{
NESIBE ARSLAN BURNAZ* \\ Department of Nutrition and Dietetics, Faculty of Health Sciences, Gumushane University, Gumushane 29100, Turkey
}

Burnaz et al.: Phenolic Composition and Antioxidant Activity of Mammillaria prolifera

\begin{abstract}
The study focuses on the comparative evaluation of extraction methods (ultrasonication and agitation) based on phenolic composition and antioxidative activities of Mammillaria prolifera and it is the first report on this subject. The effects of extraction conditions of temperature $\left(25^{\circ}\right.$ and $\left.60^{\circ}\right)$, time $(15,30$ and 60 min) and solvent type (water and $70 \%$ and $100 \%$ methanol) on total phenolic compounds, 2,2'-azinobis(3-ethylbenzothiazoline-6-sulfonic acid) and 2,2-diphenyl-1-picrylhydrazyl anti-radical activities and ferric ion reducing antioxidant power values were determined. Moreover, the phenolic acid compositions of the extracts were investigated by high performance liquid chromatography. The extracts prepared with the ultrasonic method showed stronger antioxidant activity than those prepared with agitation methods. In both methods total phenolic compounds and antioxidant activity values were the lowest in the aqueous extracts. The results showed a positive correlation observed between total phenolic compounds and antioxidant activities of the studied extracts. The optimal conditions for the extraction of phenolic compounds from Mammillaria prolifera were found as $60 \mathrm{~min}$ extraction time, $60^{\circ}$ extraction temperature and $70 \%$ methanol concentration by using the ultrasonication method. Notably, protocatechualdehyde, gallic acid, para hydroxy benzoic acid and ferulic acid were identified in Mammillaria prolifera by using the high performance liquid chromatography-diode array detector system and 14 phenolic standards. Consequently, Mammillaria prolifera cladodes can be used in food or pharmaceutical practices, as a potential natural source of antioxidants.
\end{abstract}

Key words: Mammillaria prolifera, cacti, ultrasonication extraction, agitation extraction, bioactive phenolics, high performance liquid chromatography-diode array detector

Cacti are unusual tropical, ornamental plants that originated from America and grow in most parts of the world ${ }^{[1]}$. On the other hand, cacti, which are known for minimum water requirement, grow easily in arid and unproductive soils without any care and multiply in a short time. Therefore, they can cope with drought and so they can be a repository of stress-resistant genes for other products. Cactaceae family which has more than 1500 species in nature and adapted to arid and hot lands has been widely used in food, ornamental, pharmaceutical and folk medicine fields ${ }^{[2,3]}$. The Cactaceae, a succulent plant family is divided into three subfamilies. The genus Mammillaria is a member of the Cereoideae subfamily and the largest genus in the Cactaceae family ${ }^{[4-6]}$.

*Address for correspondence

E-mail: nesibeburnaz@gumushane.edu.tr

September-October 2021
Edible or inedible plants contain thousands of different phenolic compounds that have antioxidant effects. Hence, they have become indispensable in alternative medicine to combat many diseases ${ }^{[7]}$.

Although the Mammillaria species are widely used as ornamental plants, there are studies on medicinal and industrial uses of them ${ }^{[2,8]}$. Mammillaria prolifera (Mill.) Haw. (M. prolifera) is popularly known as Texas nipple cactus, western Indian nipple cactus

This is an open access article distributed under the terms of the Creative Commons Attribution-NonCommercial-ShareAlike 3.0 License, which allows others to remix, tweak, and build upon the work non-commercially, as long as the author is credited and the new creations are licensed under the identical terms

Accepted 13 September 2021

Revised 04 June 2021

Received 05 May 2020

Indian J Pharm Sci 2021;83(5):963-973 
and strawberry cactus. Its origin is Cuba, Mexico and Texas. It has red-colored fruits, creamy-yellow colored flowers and short spines on its cladodes and it can grow up to $12 \mathrm{~cm}$ (fig. 1) ${ }^{[9]}$. This plant produces multiplexed young buds in a short time. Mammillaria cacti can grow in a short time with the emergence of new shoots on the stalk of the parent plant and extend abnormally. Some cactus species are used both as a source of food and effective medicine. They are rich in antioxidant compounds such as betaxanthin, flavonoids and polyphenols. The cacti plant appears to be an excellent source of phytochemicals of nutraceutical importance such as antioxidant active compounds, vitamins, fibers and pigments ${ }^{[10]}$. Today, several studies have indicated the worthwhile effects of phenolics and antioxidants of the cacti species. Both fruit and oil of Opuntia ficusindica are used for beneficial effects such as antioxidant, hypolipemic and antiulcerogenic activities. Cladodes of Opuntia have been studied as a treatment for gastritis, hyperglycemia, hypercholesterolemia, arteriosclerosis, diabetes, prostate hypertrophy and have been found to have a hypolipidemic effect and immune regulation function in the gastrointestinal system ${ }^{[3,11]}$. Another cactus plant Selenicereus grandiflorus has diuretic and cardiac properties ${ }^{[8]}$. Some species of cactus (e.g. Peyote cactus) which contain mescaline (intestinal softener) have been used as medicines since ancient times. Pereskia grandifolia (P. grandifolia) (Cactaceae) has been used as a natural cure in folk medicine. Leaves of $P$. grandifolia are traditionally used for the treatment of diabetes, gastric pain, ulcer, cancer, abnormal blood pressure, etc. ${ }^{[12]}$. Also, cactus pads contribute considerably to the human diet in some regions and still serve as therapeutic agents traditionally ${ }^{[13]}$.

Antioxidants play important roles such as scavenging free radicals, donating hydrogen, decomposing peroxides and chelating metal ions to prevent or delay cell damages and oxidations that cause various diseases $^{[12]}$. In recent years there are numerous studies on the use and source of natural antioxidants. They are used in many fields of industry such as food, cosmetics, pharmaceutical and paint, for color stability, shelf life and product storage ${ }^{[14,15]}$. In the food industry, especially due to nontoxicity, natural antioxidants are used as food preservatives. For this reason, today natural products especially plants that have phenolic components responsible for their antioxidative effect are being investigated in several studies ${ }^{[16]}$. The positive health effects of plant antioxidants substantially hinge on phenolic extraction methods. Thus, the right choice for the extraction method is an important step in the process of obtaining antioxidants. There are several extraction techniques including soxhlet extraction, solid-phase extraction, homogenization, microwaveassisted extraction, shaking water bath extraction, Ultrasonication Extraction (UE), supercritical fluid extraction, etc. ${ }^{[17-19]}$. Several extraction techniques have been improved to get phytochemicals from plant materials (Wang and Weller ${ }^{[20]}$. However, for industrial production, the chosen extraction technique should be simple, cost-effective and safe for both employees and consumers $^{[21]}$.

In many studies, it has been found that ultrasonication is a more effective innovative method used to reveal bioactive compounds in extracts. Both conventional and innovative extraction methods may cause degradation of targeted compounds if the selected conditions over the optimal. Therefore, the extraction conditions such as solvent type, temperature, time, etc. are also highly effective on the method ${ }^{[22]}$. Solvent type is a significant parameter that affects the recovery of phytochemicals during extraction ${ }^{[20]}$. Different concentrations of solvents such as methanol and ethanol in water have been used to extract polyphenols from plant materials ${ }^{[23]}$. For instance, Pellati et al. reported that using methanol-water mixture as a solvent in extraction was more efficient than using ethanol-water mixture to obtain polyphenols in Echinacea ${ }^{[24]}$. Another significant parameter for optimizing extraction is temperature. An increase in operating temperature generally affects extraction positively in regards to the diffusion coefficient and the solubility of the solute but also indicates that polyphenols can be denatured beyond a certain value ${ }^{[23]}$.

In the current study, it was aimed to investigate the phenolic compounds and antioxidant potentials of M. prolifera extracts obtained at different extraction conditions. To the best of my belief, this is the first report on the polyphenol content and antioxidant activity of $M$. prolifera.

\section{MATERIALS AND METHODS}

\section{Plant material:}

M. prolifera (Mill.) Haw. (International Plant Name Index, IPNI: 134999-1) is an ornamental plant that grows easily without care and multiplies in a short time (fig. 1). It was purchased from a flower store in Trabzon province in Turkey (in May 2019). The cladodes of cactus were picked up by using gloves (latex, protective standard cleaning glove, Parex) to avoid injuries from 


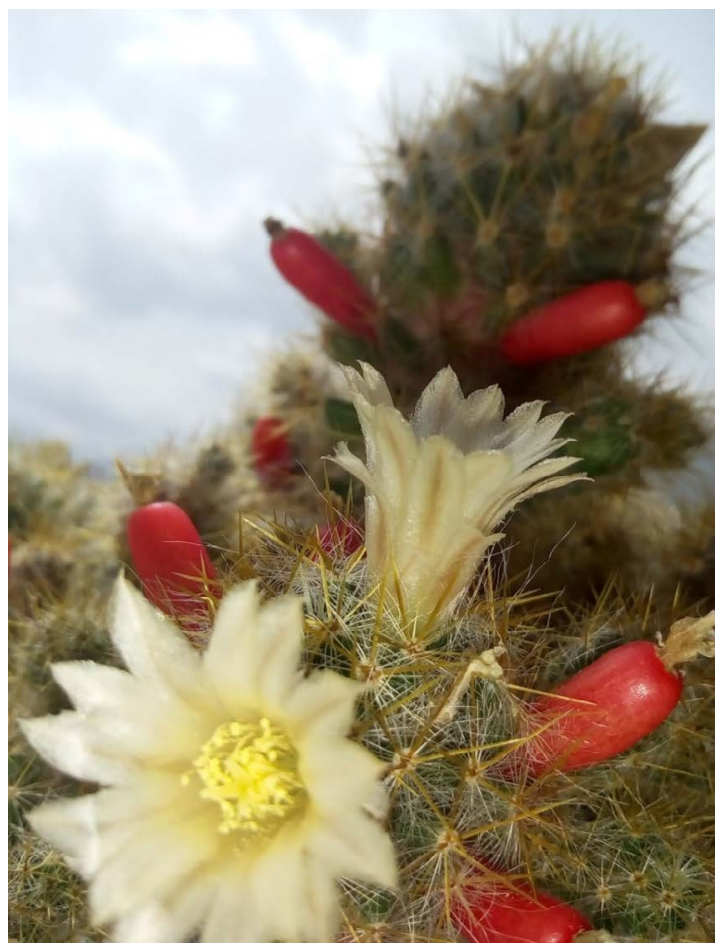

Fig. 1: Photograph of the plant M. prolifera (mill.) Haw. (6 May 2019)

its spines and then its flowers and fruits were removed. Afterwards, they were cleared of the soil with tap water. They were spread on layers of filter papers, placed in an incubator and dried at $50^{\circ}$ for $6 \mathrm{~d}$ until the reduction of the water content to $10 \%$. The dried plants ground into a fine powder in a warring blender, put into an amber glass bottle and put aside in a refrigerator at $4^{\circ}$ until extraction procedures.

\section{Chemicals and reagents:}

All chemicals and reagents used in the analyses were analytical or High Performance Liquid Chromatography (HPLC) grade and procured from Merck (Darmstadt, Germany) or Sigma-Aldrich (St. Louis, USA). Folin-Ciocalteu's reagent, 2,2'-azino-bis(3-ethylbenzothiazoline-6-sulfonic acid) (ABTS), 2,2-diphenyl-1-picrylhydrazyl (DPPH) and 2,4,6-Tris(2-pyridyl)-S-triazine (TPTZ), were procured from Merck (Darmstadt, Germany). Also, the solvents and other chemicals such as acetic acid, acetonitrile, ethanol, methanol, hydrochloric acid, anhydrous sodium carbonate, anhydrous ferric chloride and sodium acetate trihydrate were purchased from Merck (Darmstadt, Germany). Trolox ${ }^{\circledR}$ (6-hydroxy-2,5,7, 8-tetramethylchroman-2-carboxylic acid) and phenolic standards (benzoic acid, caffeic acid, chlorogenic acid, gallic acid, ferulic acid, p-coumaric acid, para hydroxy (p-OH) benzoic acid, protocatechuic acid, protocatechuic aldehyde, sinapic acid, syringic acid, syringic aldehyde, vanillic acid and vanillin) with purity $(>96 \%)$ were purchased from Sigma-Aldrich (Darmstadt, Germany).

\section{Instruments used in analyses:}

Laboratory equipment such as digital incubator (WIG50, Daihan Scientific Co. Ltd., Korea), stainless steel blender (Waring Commercial Blender, 32BL80, USA), ultrasonic bath (RK103H, Bandelin Sonorex, 140/560W, 35 kHz, Heinrichstraße, Berlin, Germany), digital precise shaking water bath (WSB-30, Wise Bath, Daihan Scientific Co. Ltd., Korea), vortex (D-91126, REAXtop Heidolph Instruments, Schwabach, Germany), analytical balance (PA214C, Ohaus, Pioneer ${ }^{\mathrm{TM}}$ Balances, Parsippany, New Jersey, USA), hotplate stirrer (MSH-20D, WiseStir Lab, Daihan Scientific Co. Ltd., Korea), centrifuge (K2015R, Benchtop Centrifuges, Centurion Scientific, UK), spectrophotometer (Shimadzu UV-1800, Japan) were used for sample preparation and extraction. Besides, conical centrifuge tube $(15 \mathrm{ml}, 17 \times 12 \mathrm{~mm}$, IsoLab, Germany), eppendorf ( $2 \mathrm{ml}$, IsoLab, Germany), syringe filter $(0.45 \mu \mathrm{m}, 25 \mathrm{~mm}$, Minisart RC 25, Sartorius Stedim Biotech, Germany) and black band filter paper (Whatman No.1, ashless black ribbon, 589/1) were used.

The phenolic acid characterization analyses were determined by an HPLC instrument (1100 series, Agilent Technologies, Waldbronn, Germany) using a Hichrom C18 reverse phase column $(250 \mathrm{~mm} \times 4.6 \mathrm{~mm}$ internal diameter (i.d.) $5 \mu \mathrm{m}$ particle size, UK). The HPLC system consisted of a quaternary solvent pump (G1311A), a degasser (G13179A) and a diode array detector (DAD/G1315D). A manual injector (25 $\mu 1$, Hamilton, Reno, Nevada, USA) was used.

\section{Extraction methods and sample preparation:}

Two different extraction methods, ultrasonication and agitating were used in the current study. The performance of ultrasonication was compared to that of the agitation method frequently used in our laboratory. In addition, the combination of different extraction parameters including extraction temperature $\left(25^{\circ}, 60^{\circ}\right)$, time $(15,30$ and $60 \mathrm{~min})$ and methanol percentage in an aqueous solvent $(0,70$ and $100 \%)$ was utilized for the preparation of the extracts. 18 extracts were prepared for each extraction method.

Ultrasonication Extraction (UE): The extraction efficiency hinges on both the extraction method and the extraction solvent. In published articles, for the 
extraction of phenolic compounds from plant material, different solvent systems (polar, apolar or a mixture of several solvents) have been used. In a study methanol was found as the most selective for extracting phenolic compounds from red grape by products ${ }^{[25]}$. As specified, methanol was chosen as the extraction solvent because of its widespread usage in different phenolic extraction processes from various plant materials. So, two different concentrations of methanol $(70 \%$ and $100 \%)$ and ultrapure water $(0 \%$ methanol) were used as a solvent in the preparation of the extracts. $1 \mathrm{~g}$ of powdered $M$. prolifera was weighed in a centrifuge tube and $10 \mathrm{ml}$ of solvent was added. Thereafter, the cap of each centrifuge tube was closed and the ultrasonic water bath firstly adjusted to $25^{\circ}$ and nine of the samples put into the bath. Samples upon completion of extraction time (at 15, 30 and $60 \mathrm{~min}$ ) were removed from the ultrasonic bath. The same process was applied at $60^{\circ}$ and the following nine samples were obtained. Finally, all the samples were centrifuged at $5000 \mathrm{rpm}$ and $4^{\circ}$ for $10 \mathrm{~min}$. The obtained extracts were filtered off. Then, each filtrate was collected and completed to $10 \mathrm{ml}$ volume with related solvents (methanol, $70 \%$ methanol, or ultrapure water). The extracts were divided into eppendorf tubes and stored in the refrigerator at $-18^{\circ}$ for later analysis.

Agitation Extraction (AE): $1 \mathrm{~g}$ of powdered M. prolifera was weighed in a centrifuge tube and $10 \mathrm{ml}$ of solvent was added on, as in the UE method. Then, various concentrations of methanol $(70 \%$ or $100 \%)$ and ultrapure water ( $0 \%$ methanol) were used as a solvent in the preparation of the extracts.

Thereafter, all processes were repeated as in the UE method. In analyses, the samples were tested in triplicate. Also, reagent and sample blinds were used for each sample.

\section{Analysis of bioactive compounds:}

Total Phenolic Compounds (TPC) content: TPC values of the extracts were determined by using the Folin-Ciocalteu method ${ }^{[26]}$. Concisely, $0.5 \mathrm{ml}$ reagent solution $(0.2 \mathrm{~N})$ was added over each $0.1 \mathrm{ml}$ extract solution and incubated in dark for $5 \mathrm{~min}$. Thereafter, $0.4 \mathrm{ml}$ of anhydrous sodium carbonate (1 M) solution and $4 \mathrm{ml}$ of distilled water were added and the test tubes were vortexed at every stage. The test tubes were waited at room temperature and in dark. After $1 \mathrm{~h}$, the absorbance was measured at $765 \mathrm{~nm}$. The absorbance values were evaluated as the average of three measurements and the sample and reactive blank values were subtracted from this average. With the obtained data from the gallic acid standard, a calibration graph was formed. The TPC values were obtained from the gallic acid standard calibration curve, $y=0.0018 \mathrm{x}$ with $\mathrm{R}^{2}=0.9993$, where $\mathrm{x}$ is the net absorbance value and $\mathrm{y}$ is the concentration of gallic acid standard dissolved in methanol ranging from 0 to $0.2 \mathrm{mg} / \mathrm{ml}$. The TPC content was expressed as mg gallic acid/g sample Dry Weight (DW).

\section{Antioxidant activity:}

ABTS $^{++}$assay: The $\mathrm{ABTS}^{-+}$radical scavenging activity was performed according to a previously described method ${ }^{[27]}$. The stable $\mathrm{ABTS}^{\cdot+}$ radical cation stock solution was obtained by mixing $7 \mathrm{mM}$ ABTS solution with $2.45 \mathrm{mM}$ potassium persulfate solution in pure water. The prepared solution was kept at room temperature in dark for $16 \mathrm{~h}$. Then the solution was diluted with ethanol until the absorbance reached $0.70( \pm 0.02)$ absorbance units $(\mathrm{Au})$ at $734 \mathrm{~nm}$. Trolox ${ }^{\circledR}$ (in methanol) was used as an antioxidant standard. Briefly, a total of $1950 \mu \mathrm{l}$ of $\mathrm{ABTS}^{++}$solution was added on $50 \mu \mathrm{standard} / \mathrm{extract}$, incubated for $20 \mathrm{~min}$ at room temperature, in dark. Then the absorbance was read at $734 \mathrm{~nm}$. The Trolox ${ }^{\circledR}$ Equivalent Antioxidant Capacity (TEAC) values and scavenging percentages (\%) were obtained from Trolox ${ }^{\circledR}$ standard calibration curve, $y=0.0009 x$ with $R^{2}=0.9816$, where $x$ is the net absorbance value and $y$ is the concentration of Trolox ${ }^{\circledR}$ standard. The results were calculated and expressed as $\mu \mathrm{M}$ TEAC. Also, the $\mathrm{ABTS}^{-+}$scavenging percentage was calculated as follows:

Scavenging activity $(\%)=\mathrm{Abs}_{\mathrm{B}}-\mathrm{Abs}_{\mathrm{A}} / \mathrm{Abs}_{\mathrm{A}} \times 100$ (Eq. 1)

where, $\mathrm{A}$ is the absorbance of the blank ABTS solution $(\mathrm{t}=0 \mathrm{~min})$ and $\mathrm{B}$ is the absorbance of the tested extract solution ( $\mathrm{t}=20 \mathrm{~min})$.

DPPH• assay: The DPPH• radical scavenging activity was performed according to a previously described method, with a small modification ${ }^{[28]}$. The purple $\mathrm{DPPH} \cdot$ radical solution is turned into yellow color when reacted with an antioxidant that can give hydrogen atom. Firstly, $100 \mu \mathrm{M}$ DPPH• radical solution (in methanol) was prepared and stirred approximately for $40 \mathrm{~min}$ in a magnetic stirrer before use. Trolox ${ }^{\circledR}$ (in methanol) was used as an antioxidant standard. For analysis, a total of $2.9 \mathrm{ml} \mathrm{DPPH}$ radical solution $(100 \mu \mathrm{M})$ was added to $50 \mu$ of standard/extract and vortexed. After $1 \mathrm{~h}$ of incubation period in dark at room temperature, the absorbance was read at $515 \mathrm{~nm}$. The TEAC values 
and scavenging percentages (\%) were obtained from Trolox $^{\circledR}$ standard calibration curve, $\mathrm{y}=0.0006 \mathrm{x}$ with $\mathrm{R}^{2}=0.9991$, where $\mathrm{x}$ is the net absorbance value and $y$ is the concentration of Trolox ${ }^{\circledR}$ standard $(\mu \mathrm{M})$. The results were calculated and expressed as $\mu \mathrm{M}$ TEAC and $\mathrm{DPPH} \bullet$ scavenging percentage. $\mathrm{DPPH} \bullet$ scavenging percentage was calculated as follows:

Scavenging activity $(\%)=\mathrm{Abs}_{\mathrm{B}}-\mathrm{Abs}_{\mathrm{A}} / \mathrm{Abs}_{\mathrm{B}} \times 100$ (Eq. 2)

where, $\mathrm{A}$ is the absorbance of the blank DPPH solution $(\mathrm{t}=0 \mathrm{~min})$ and $\mathrm{B}$ is the absorbance of the tested extract solution ( $\mathrm{t}=60 \mathrm{~min})$.

\section{Ferric Ion Reducing Antioxidant Power (FRAP)} assay: FRAP assay was performed according to a previously described method ${ }^{[29]}$, with some modifications ${ }^{[30]}$. The light brown ferric cation $\left(\mathrm{Fe}^{3+}-\right.$ TPTZ is reduced and turned into the blue $\mathrm{Fe}^{2+}-\mathrm{TPTZ}$ complex in the presence of antioxidants and this complex gives maximum absorbance at $595 \mathrm{~nm}$. Three solutions were prepared to perform the FRAP assay: an acetate buffer solution ( $\mathrm{pH}$ 3.6), $10 \mathrm{mM}$ TPTZ solution in $40 \mathrm{mM}$ Hydrochloric acid $(\mathrm{HCl})$ and $20 \mathrm{mM}$ ferric chloride solution in water. The solutions were mixed carefully in a ratio of 10:1:1 to obtain the fresh FRAP reagent solution. Trolox ${ }^{\circledR}$ (in methanol) was used as an antioxidant standard. For analysis, a total of $1450 \mu 1$ fresh FRAP solution was added on $50 \mu \mathrm{l}$ of standard/ extract and vortexed. After 20 min incubation at room temperature, the absorbances were read at $595 \mathrm{~nm}$. The TEAC values were obtained from Trolox ${ }^{\circledR}$ standard calibration curve, $\mathrm{y}=0.0011 \mathrm{x}$ with $\mathrm{R}^{2}=0.9986$, where $\mathrm{x}$ is the net absorbance value and $\mathrm{y}$ is the concentration of Trolox ${ }^{\circledR}$ standard $(\mu \mathrm{M})$. The results were calculated and expressed as $\mu \mathrm{M}$ TEAC. The samples/standards were studied in triplicates. In this method, the increased absorbance value, hence the corresponding TEAC value, indicates the increased reducing power.

FRAP value $=\mu \mathrm{M}$ Trolo ${ }^{\circledR}$ concentration corresponding to sample absorbance.

\section{HPLC analysis of phenolics:}

HPLC runs for the separation of polyphenols were carried out at $25^{\circ}$, room temperature. The flow rate was $0.7 \mathrm{ml} / \mathrm{min}$ and the injection volume was $20 \mu 1$ for all standard mixtures and samples. HPLC-DAD analysis for the identification of phenolic acids was carried out by using a previously validated method described by Burnaz et al. ${ }^{[31]}$. Data acquisition (Retention Time (RT), peak area, peak width, peak height, etc.) was performed by using Agilent ChemStation Software Program. Three different solvents were prepared for the gradient elution program as solvent $\mathrm{A}$ (water/acetonitrile/acetic acid, 49.75/49.75/0.5, v/v/v), solvent B (acetic acid/ water, 2.0/98.0, v/v) and solvent $\mathrm{C}$ (acetonitrile, $100 \%$ ) shown in Table 1. Phenolic compounds of M. prolifera were identified by comparing their RTs with those of fourteen phenolic standards. Moreover, the results were confirmed by comparing the peak spectra at the same RT. The results were expressed as percentage (\%) peak area and peak area in terms of mAU*min (mAU: milli absorbance unit). All phenolic standards were prepared by using a $40 \%$ methanol solution.

\section{Statistical analysis:}

The phenolic content and antioxidant activity analyses were performed in triplicate. Thereafter, results were expressed as mean \pm Standard deviation (SD). A statistical program (Statistical Package for the Social Sciences (SPSS) statistics software for Windows, Version 25.0, IBM ${ }^{\circledR}$, New York, USA) was used for data processing. The TPC, ABTS, DPPH and FRAP analyses results (Table 2 and Table 3) were compared by using one way Analysis of Variance (ANOVA) "Post hoc multiple comparisons", Least Significant Difference (LSD) and Duncan's tests.

\section{RESULTS AND DISCUSSION}

In the current study, three different extraction times $(15,30$ and $60 \mathrm{~min})$ were applied in both extraction methods (UA and $\mathrm{AE}$ ) at $25^{\circ}$ and $60^{\circ}$ with different methanol concentrations $(0 \%, 70 \%$ and $100 \%)$. The TPC and antioxidant potentials of the obtained extracts (36 samples) of M. prolifera were shown in Table 2 and Table 3. The phenolic content was determined by FolinCiocalteau's method and antioxidant potential was determined by three complementary methods (ABTS, DPPH and FRAP).

First, the effect of the extraction technique was

TABLE 1: HPLC GRADIENT ELUTION PROGRAM APPLIED FOR $M$. prolifera EXTRACTS

\begin{tabular}{|c|c|c|c|}
\hline Time $(\min )$ & Solvent $A^{*}(\%)$ & Solvent B* (\%) & Solvent C* (\%) \\
\hline 0 & 10 & 90 & 0 \\
\hline 28 & 50 & 50 & 0 \\
\hline 32 & 90 & 10 & 0 \\
\hline 35 & 20 & 0 & 80 \\
\hline 42 & 20 & 0 & 80 \\
\hline 44 & 10 & 90 & 0 \\
\hline 45 & 10 & 90 & 0 \\
\hline
\end{tabular}

Note: *Solvent A: Acetic acid/water/acetonitrile (0.5/49.75/49.75 $\mathrm{v} / \mathrm{v} / \mathrm{v})$; Solvent B: Acetic acid/water $(2.0 / 98.0 \mathrm{v} / \mathrm{v})$; Solvent C: HPLC grade acetonitrile (100\%) 
examined. The selection of extraction technique plays an important role in the extraction of phenolic compounds and other antioxidants from the plant matrix.

The effects of UA and $\mathrm{AE}$ techniques at different conditions on the TPCs and antioxidant activities of $M$. prolifera were presented in Table 2 and Table 3, respectively. The TPCs and antioxidant activity values of samples showed differences with respect to the extraction techniques. The UE technique was found to be more effective than the $\mathrm{AE}$ technique at the same extraction conditions. When the AE and UE extracts were compared in terms of their phenolic and antioxidant potential values, most of their results showed linearity.

The TPCs of the extracts were ranged from 22.8 to $107.4 \mathrm{mg}$ Gallic Acid Equivalents (GAE)/g DW for $\mathrm{UE}$ and from 1.5 to $68.8 \mathrm{mg}$ GAE/g DW for AE. The ABTS values of the extracts were ranged from 232.6 to $695.1 \mu \mathrm{M}$ TEAC for UE and from 53.3 to $460.7 \mu \mathrm{M}$ TEAC for AE. The DPPH values of the extracts were ranged from 51.1 to $315.2 \mu \mathrm{M}$ TEAC for UE and from 3.9 to $260.5 \mu \mathrm{M}$ TEAC for AE. The FRAP values of the extracts were ranged from 96.7 to $584.3 \mu \mathrm{M}$ TEAC for $\mathrm{UE}$ and from 13.0 to $484.5 \mu \mathrm{M}$ TEAC for AE.
According to a study carried out by Musa et al. the antioxidant assay values of the guava fruit extract obtained by using the ultrasonic technique were higher than the shaking technique ${ }^{[32]}$. In a study, Keskin et al. investigated the pectin recovery from Trachystemon orientalis L. by using conventional acid hydrolysis and ultrasound-assisted acid hydrolysis extraction techniques with different acids. They have noticed that the ultrasound-assisted acid hydrolysis with Sulphuric acid $\left(\mathrm{H}_{2} \mathrm{SO}_{4}\right)$ was the best acid for the pectin known to exhibit antioxidant activity ${ }^{[33]}$.

In another study on the effect of ultrasonication on the TPC and antioxidant activity values of various seeds cakes, the researchers reported that the ultrasonic extraction method was quite better than the conventional extraction method ${ }^{[34]}$. The number of articles supporting this finding in the literature has increased in the last decade $^{[35-37]}$.

Different solvents can be used for the extraction of polyphenols from plant materials. Regarding this, in a study that was performed to obtain the natural antioxidants from the rice bran by optimizing the ultrasonic-assisted extraction, it was found that under the same extraction conditions, methanol gave better

TABLE 2: TOTAL PHENOLIC CONTENTS AND ANTIOXIDANT ACTIVITIES OF $M$. prolifera EXTRACTS OBTAINED USING UE TECHNIQUE WITH DIFFERENT CONDITIONS

\begin{tabular}{|c|c|c|c|c|c|c|c|c|c|}
\hline $\begin{array}{l}\text { Sample } \\
\text { No. }\end{array}$ & $\begin{array}{c}\text { Methanol } \\
\text { concen } \\
\text {-tration (\%) } \\
\text { in solvent } \\
\end{array}$ & $\begin{array}{c}\text { Extraction } \\
\text { temperature } \\
\left({ }^{\circ}\right)\end{array}$ & $\begin{array}{l}\text { Extraction } \\
\text { Time (min) }\end{array}$ & $\begin{array}{c}\mathrm{TPC}^{*} \\
\mathrm{mg} \mathrm{GAE} / \mathrm{g} \\
\text { DW }\end{array}$ & $\begin{array}{c}\text { ABTS* } \\
\mu M \text { TEAC }\end{array}$ & $\begin{array}{l}\text { ABTS } \\
\text { scaven- } \\
\text { ging \% }\end{array}$ & $\begin{array}{c}\text { DPPH* }^{*} \\
\mu M \text { TEAC }\end{array}$ & $\begin{array}{c}\text { DPPH } \\
\text { scaven- } \\
\text { ging \% }\end{array}$ & $\begin{array}{c}\text { FRAP* }^{*} \\
\mu M \text { TEAC }\end{array}$ \\
\hline 1 & 0 & 25 & 15 & $28.3^{\circ} \pm 0.2$ & $243.7^{\mathrm{jk}} \pm 3.9$ & 32.1 & $54.5^{g} \pm 11.1$ & 4.7 & $125.0^{h} \pm 5.0$ \\
\hline 2 & & & 30 & $30.3^{n} \pm 0.4$ & $255.6^{j} \pm 3.9$ & 55.7 & $62.2^{\mathrm{g}} \pm 3.9$ & 5.4 & $130.9^{h} \pm 7.8$ \\
\hline 3 & & & 60 & $38.2^{m} \pm 0.3$ & $275.6^{i} \pm 4.8$ & 54.1 & $70.0^{\circ} \pm 12.6$ & 6.1 & $139.5^{h} \pm 4.7$ \\
\hline 4 & & 60 & 15 & $43.5^{\mathrm{j}} \pm 0.4$ & $306.7^{\mathrm{h}} \pm 12.8$ & 53.1 & $130.6^{f} \pm 10.9$ & 11.4 & $188.6^{9} \pm 4.5$ \\
\hline 5 & & & 30 & $67.2^{\mathrm{d}} \pm 0.4$ & $354.5^{5} \pm 16.8$ & 49.6 & $155.0^{\mathrm{ef}} \pm 30.9$ & 13.5 & $314.8^{\mathrm{d}} \pm 10.3$ \\
\hline 6 & & & 60 & $22.8^{\mathrm{p}} \pm 0.2$ & $232.6^{k} \pm 3.9$ & 56.4 & $51.1^{\mathrm{g}} \pm 16.4$ & 4.5 & $96.7^{i} \pm 10.4$ \\
\hline 7 & 70 & 25 & 15 & $43.3^{j \mathrm{k}} \pm 0.2$ & $393.2^{\mathrm{e}} \pm 7.2$ & 52.9 & $130.0^{f} \pm 14.8$ & 11.0 & $187.1^{\mathrm{g}} \pm 7.0$ \\
\hline 8 & & & 30 & $45.2^{i} \pm 0.2$ & $401.7^{\mathrm{de}} \pm 6.9$ & 54.1 & $131.1^{\mathrm{f}} \pm 6.3$ & 11.2 & $190.8^{\mathrm{g}} \pm 5.2$ \\
\hline 9 & & & 60 & $63.5^{\mathrm{e}} \pm 0.7$ & $412.5^{\mathrm{d}} \pm 7.1$ & 55.5 & $200.6^{c} \pm 2.6$ & 17.1 & $332.9^{c} \pm 23.9$ \\
\hline 10 & & 60 & 15 & $50.8^{\mathrm{h}} \pm 0.6$ & $425.8^{c} \pm 2.8$ & 57.3 & $181.1^{\mathrm{cd}} \pm 6.7$ & 15.4 & $250.2^{\mathrm{ef}} \pm 6.1$ \\
\hline 11 & & & 30 & $90.7^{c} \pm 0.4$ & $683.9^{\mathrm{a}} \pm 1.1$ & 92.1 & $305.6^{\mathrm{a}} \pm 22.2$ & 26.0 & $234.3^{f} \pm 1.2$ \\
\hline 12 & & & 60 & $107.4^{\mathrm{a}} \pm 0.3$ & $695.1^{\mathrm{a}} \pm 1.1$ & 93.6 & $315.2^{\mathrm{a}} \pm 1.4$ & 26.8 & $584.3^{\mathrm{a}} \pm 14.9$ \\
\hline 13 & 100 & 25 & 15 & $40.0^{\prime} \pm 0.4$ & $283.3^{i} \pm 2.2$ & 38.1 & $127.2^{f} \pm 2.1$ & 10.9 & $178.3^{g} \pm 1.8$ \\
\hline 14 & & & 30 & $42.7^{k} \pm 0.6$ & $313.7^{h} \pm 5.7$ & 42.2 & $133.9^{f} \pm 11.6$ & 11.5 & $187.3^{\mathrm{g}} \pm 2.5$ \\
\hline 15 & & & 60 & $53.3^{g} \pm 0.4$ & $397.4^{\mathrm{e}} \pm 10.3$ & 53.5 & $181.1^{\mathrm{cd}} \pm 14.2$ & 15.5 & $239.8^{\mathrm{ef}} \pm 1.8$ \\
\hline 16 & & 60 & 15 & $57.9^{f} \pm 0.3$ & $375.2^{f} \pm 12.9$ & 50.5 & $173.3^{\mathrm{de}} \pm 14.4$ & 14.9 & $255.0^{\mathrm{e}} \pm 4.5$ \\
\hline 17 & & & 30 & $103.9^{b} \pm 0.7$ & $503.3^{\mathrm{b}} \pm 12.4$ & 67.7 & $278.9^{b} \pm 10.9$ & 23.9 & $248.1^{\text {ef }} \pm 13.7$ \\
\hline 18 & & & 60 & $107.0^{\mathrm{a}} \pm 0.3$ & $687.8^{\mathrm{a}} \pm 2.2$ & 92.5 & $312.2^{\mathrm{a}} \pm 5.0$ & 26.8 & $511.9^{\mathrm{b}} \pm 17.0$ \\
\hline
\end{tabular}

Note: "Values represent the mean $\pm \mathrm{SD},(\mathrm{N}=3)$. Values followed by different superscript letters in the same column are significantly different from each other (Duncan's test, $p<0.05$ ). GAE: Gallic acid equivalent; TEAC: Trolox ${ }^{\circledR}$ equivalent antioxidant capacity; DW: Dry weight 
TABLE 3: TOTAL PHENOLIC CONTENTS AND ANTIOXIDANT ACTIVITIES OF $M$. prolifera EXTRACTS OBTAINED USING AE TECHNIQUE WITH DIFFERENT CONDITIONS

\begin{tabular}{|c|c|c|c|c|c|c|c|c|c|}
\hline $\begin{array}{l}\text { Sample } \\
\text { No. }\end{array}$ & $\begin{array}{l}\text { Methanol } \\
\text { concen- } \\
\text { tration (\%) } \\
\text { in solvent }\end{array}$ & $\begin{array}{c}\text { Extraction } \\
\text { tempe- } \\
\text { rature }\left({ }^{\circ}\right)\end{array}$ & $\begin{array}{l}\text { Extraction } \\
\text { time (min) }\end{array}$ & $\begin{array}{c}\text { TPC* } \\
\text { mg GAE/g } \\
\text { DW }\end{array}$ & $\begin{array}{c}\text { ABTS* } \\
\mu M \text { TEAC }\end{array}$ & $\begin{array}{l}\text { ABTS } \\
\text { scaven- } \\
\text { ging \% }\end{array}$ & $\begin{array}{c}\text { DPPH* }^{*} \\
\mu M \text { TEAC }\end{array}$ & $\begin{array}{c}\text { DPPH } \\
\text { scavenging } \\
\%\end{array}$ & $\begin{array}{c}\text { FRAP* } \\
\mu M \text { TEAC }\end{array}$ \\
\hline 19 & 0 & 25 & 15 & $1.5^{\mathrm{p}} \pm 0.4$ & $53.3^{n} \pm 3.9$ & 7.2 & $3.9^{k} \pm 1.9$ & 0.3 & $13.0^{n} \pm 2.1$ \\
\hline 20 & & & 30 & $5.3^{\mathrm{no}} \pm 0.5$ & $129.3^{\mathrm{m}} \pm 3.3$ & 17.3 & $28.9^{j} \pm 17.0$ & 2.1 & $68.2^{\mathrm{m}} \pm 2.2$ \\
\hline 21 & & & 60 & $6.6^{m} \pm 0.3$ & $163.3^{\mathrm{k}} \pm 2.8$ & 21.9 & $36.1^{\mathrm{j}} \pm 9.2$ & 3.1 & $70.3^{m} \pm 1.1$ \\
\hline 22 & & 60 & 15 & $14.7^{\mathrm{j}} \pm 0.5$ & $189.3^{i} \pm 4.0$ & 25.4 & $62.8^{\mathrm{hi}} \pm 5.8$ & 5.5 & $72.4^{\mathrm{m}} \pm 11.5$ \\
\hline 23 & & & 30 & $44.4^{\mathrm{d}} \pm 0.7$ & $323.7^{f} \pm 1.9$ & 43.4 & $132.2^{f} \pm 3.5$ & 11.5 & $172.7^{\mathrm{g}} \pm 8.1$ \\
\hline 24 & & & 60 & $9.9^{1} \pm 0.4$ & $174.4^{j} \pm 2.8$ & 23.4 & $40.0^{j} \pm 13.0$ & 3.5 & $102.7^{\mathrm{kl}} \pm 2.4$ \\
\hline 25 & 70 & 25 & 15 & $10.8^{\mathrm{k}} \pm 0.5$ & $227.4^{\mathrm{h}} \pm 2.8$ & 30.8 & $43.9^{i j} \pm 13.0$ & 3.9 & $140.3^{i} \pm 0.5$ \\
\hline 26 & & & 30 & $28.2^{\mathrm{g}} \pm 0.4$ & $295.9^{g} \pm 4.6$ & 40.1 & $153.9^{\mathrm{de}} \pm 12.0$ & 13.6 & $153.1^{\mathrm{hi}} \pm 7.7$ \\
\hline 27 & & & 60 & $32.6^{f} \pm 0.4$ & $298.9^{9} \pm 15.6$ & 40.5 & $161.7^{d} \pm 8.6$ & 14.2 & $158.2^{\mathrm{gh}} \pm 1.6$ \\
\hline 28 & & 60 & 15 & $19.5^{i} \pm 0.6$ & $317.8^{f} \pm 11.5$ & 43.1 & $136.7^{\mathrm{ef}} \pm 31.3$ & 12.0 & $272.1^{\mathrm{e}} \pm 3.7$ \\
\hline 29 & & & 30 & $43.3^{e} \pm 0.6$ & $434.1^{\mathrm{e}} \pm 3.2$ & 58.8 & $196.1^{c} \pm 14.0$ & 17.3 & $378.2^{\mathrm{d}} \pm 12.3$ \\
\hline 30 & & & 60 & $67.6^{\mathrm{b}} \pm 06$ & $447.0^{\mathrm{b}} \pm 3.2$ & 60.6 & $235.0^{\mathrm{b}} \pm 4.2$ & 20.7 & $464.2^{b} \pm 8.4$ \\
\hline 31 & 100 & 25 & 15 & $4.6^{\circ} \pm 0.4$ & $143.3^{\prime} \pm 7.1$ & 25.1 & $63.3^{\mathrm{h}} \pm 1.0$ & 5.4 & $90.0^{\prime} \pm 2.4$ \\
\hline 32 & & & 30 & $5.7^{n} \pm 0.5$ & $186.7^{\mathrm{i}} \pm 3.4$ & 25.6 & $71.1^{\mathrm{gh}} \pm 3.5$ & 6.1 & $114.5^{\mathrm{jk}} \pm 2.4$ \\
\hline 33 & & & 60 & $7.4^{\mathrm{m}} \pm 0.3$ & $190.7^{i} \pm 6.7$ & 19.3 & $85.0^{g} \pm 12.5$ & 7.3 & $123.0^{j} \pm 12.4$ \\
\hline 34 & & 60 & 15 & $25.9^{h} \pm 0.5$ & $353.0^{\mathrm{e}} \pm 2.9$ & 56.9 & $170.6^{d} \pm 6.0$ & 19.4 & $232.1^{f} \pm 5.3$ \\
\hline 35 & & & 30 & $45.4^{c} \pm 0.5$ & $423.3^{d} \pm 6.1$ & 47.4 & $225.6^{\mathrm{b}} \pm 3.3$ & 14.7 & $444.5^{c} \pm 18.1$ \\
\hline 36 & & & 60 & $68.8^{\mathrm{a}} \pm 0.4$ & $460.7^{a} \pm 3.3$ & 61.9 & $260.5^{a} \pm 5.8$ & 22.4 & $484.5^{\mathrm{a}} \pm 20.8$ \\
\hline
\end{tabular}

Note: "Values represent the mean $\pm \mathrm{SD},(\mathrm{N}=3)$. Values followed by different superscript letters in the same column are significantly different from each other (Duncan's test, $\mathrm{p}<0.05$ ). GAE: Gallic acid equivalent; TEAC: Trolox ${ }^{\circledR}$ equivalent antioxidant capacity; DW: Dry weight

results than hexane, ethyl acetate and ethanol ${ }^{[38]}$. Thereby, three different concentrations of methanol were used as solvents in this study.

In this study, at $25^{\circ}, \mathrm{TPC}, \mathrm{ABTS}, \mathrm{DPPH}$ and FRAP values of both $\mathrm{UE}$ and $\mathrm{AE}$ increased in the following order: $70 \%$ methanol $>100 \%$ methanol $>100 \%$ water ( $0 \%$ methanol) linearly, but the values differed at $60^{\circ}$ and showed no correlation with those observed at $25^{\circ}$. Especially, the extracts prepared at $25^{\circ}$ with $70 \%$ methanol exhibited significantly higher TPC, ABTS and FRAP values than $100 \%$ methanol and aqueous extracts. However, DPPH and FRAP values were nearly the same for $70 \%$ and $100 \%$ methanol extracts. These values were not significantly affected by methanol concentration change from $70 \%$ to $100 \%$. Although the TPC, ABTS, DPPH and FRAP values of $100 \%$ methanolic extracts were higher at $60^{\circ}$, they showed close values with $70 \%$ methanol extracts in UE and AE.

In a study, Anwar and Przybylski investigated the effect of different solvents on TPC and antioxidant potentials of flaxseed extracts ${ }^{[39]}$. They have noticed that the flaxseed extract obtained with $80 \%$ aqueous methanol involved the highest amount of phenolic content when compared to $100 \%$ methanolic and other extracts. In a similar study, Turkmen et al. researched the solvent concentration effect on TPC and antioxidant activities of black and mate tea extracts. They used three different concentrations $(50 \%, 80 \%$ and $100 \%)$ of various solvents, including methanol and reported that $50 \%$ methanolic extracts involved the highest level of TPC and DPPH scavenging activity and followed by 80 $\%$ and $100 \%$ methanolic extracts, in the respective order ${ }^{[40]}$.

Disparately, in another study on the effect of solvent in the extraction, to determine the total phenolic content and antioxidant capacity of Limnophila aromatica, $100 \%$ methanolic extracts were found to show the highest TPC values and followed by $50 \%$ and $75 \%$ methanolic extracts. Besides, DPPH antiradical activities of methanolic extracts were ordered as: $75 \%>100 \%>50 \%$ methanolic extracts ${ }^{[41]}$. Mokrani and Madani investigated the effect of the solvent type, time and temperature on the antioxidant activity of peach and they have reported that the extraction temperature at the range of $25^{\circ}-70^{\circ}$ was not significantly different for DPPH \% scavenging as in the case with FRAP values ${ }^{[42]}$. Moreover, they noticed that $60 \%$ acetone was significantly the most efficient for DPPH 
scavenging activity and FRAP values of peach extracts followed by $60 \%$ methanol, $60 \%$ water and $60 \%$ ethanol, respectively. Espada-Bellido et al. studied the phenolic compounds in mulberry pulp by ultrasoundassisted extraction. They found that $61 \%$ methanol at $64^{\circ}$ and 10 min extraction was the optimum conditions for $\mathrm{TPC}^{[22]}$.

Similar to the current study results, Musa et al. found that the effect of the methanol concentration for extracting TPC and antioxidant activity of guava fruit in the best manner and the order was $50 \%$ methanol $>70 \%$ methanol $>100 \%$ methanol ${ }^{[25]}$.

It can be seen from the literature that it is too difficult to decide a standard suitable solvent for the extraction of all antioxidant compounds from plants.

Temperature is another main parameter affecting the extraction efficacy. The increasing temperature may support extraction by breaking down the cell walls and raise the solubility of phenolics in the solvent ${ }^{[43]}$. As a result, the extraction rate of compounds may increase.

In this study, the increase in extraction time with temperature harmed the quantity of phenolics above $60^{\circ}$ in the aqueous sample. However, for obtaining the best TPC, ABTS, DPPH and FRAP values from the other extracts, $60^{\circ}$ is better than room temperature $\left(25^{\circ}\right)$. Rodrigues et al. investigated the optimal conditions to get phenolic compounds through the coconut shell powder by using an ultrasound extraction technique. They have reported that at $60 \mathrm{~min}$ extraction time, phenolic contents of the extracts were affected linearly by the increasing extraction temperature as $60^{\circ}>45^{\circ}>20^{\circ}$ extracts $^{[44]}$.

In another study on ultrasound extraction effect on phenolic compounds of citrus peel extracts, researchers found that during the 60 min extraction period, increasing the temperature from $15^{\circ}$ to $40^{\circ}$ resulted in a two-fold increase in the amounts of phenolic compounds ${ }^{[32]}$. In a study conducted by Chan et al. about the optimization extraction conditions for phenolic compounds of Limau purut peels, it was reported that TPC values of the extracts increased with the temperature rise from $25^{\circ}$ to $40^{\circ}$, but the values decreased after the temperatures reached $60^{\circ[45]}$. In another study, the extraction temperatures $\left(40^{\circ}, 50^{\circ}, 60^{\circ}\right.$ and $\left.70^{\circ}\right)$ were compared in terms of total phenolics, DPPH and FRAP and it was found that the investigated values increased linearly from $40^{\circ}$ to $60^{\circ}$, but decreased at $70^{\circ[34]}$.

Vuong et al. studied the optimization of conditions for the extraction of catechins from green tea and noticed that increasing extraction temperature affected positively the yield of individual catechins until reaching $80^{\circ}$ for $30 \mathrm{~min}^{[46]}$. Although many studies in the literature yielded better results for extracting phenolic compounds at $60^{\circ}$ when compared to the lower temperatures, it was stated that parameters such as various solvent systems and extraction time may cause denaturation of phenolic compounds and thermal degradation ${ }^{[47]}$.

In the current study, the TPC, ABTS, DPPH and FRAP values increased with the extraction time, except for aqueous samples at $60^{\circ}$. The use of higher temperatures and increasing the treatment time may lead to a degradation of phenolic compounds and anthocyanins and the reduction of phenolic content for aqueous samples $^{[48]}$. Almost in all cases in both extraction techniques (UE and AE), TPC and antioxidant TEAC values (results of ABTS, DPPH and FRAP assays) increased with increasing extraction time at $25^{\circ}$ and $60^{\circ}$, except aqueous extracts. Although there was a significant difference between TPC values of extracts with increasing extraction time from $30 \mathrm{~min}$ to $60 \mathrm{~min}$ at $25^{\circ}$, there was no significant difference between ABTS, DPPH and FRAP values of the extracts at the same conditions in general. Especially, at the extraction temperature of $60^{\circ}$, the $\mathrm{ABTS}^{\circ+}$ scavenging activities of aqueous extracts were affected negatively from the increasing extraction time, from $30 \mathrm{~min}$ to $60 \mathrm{~min}$. This result may be related to the possible degradation of some antioxidant substances in the extract in the aqueous environment and at $60^{\circ}$ due to the prolongation of extraction time.

In a study, investigated by Rodrigues et al. it was reported that the phenolics of coconut UE extracts at $60^{\circ}$ were affected linearly from the increasing extraction time $(20,40 \text { and } 60 \mathrm{~min})^{[44]}$. In a study performed by Teh and Birch, it was found that phenolic content, DPPH and FRAP values increased together with extraction time from $20 \mathrm{~min}$ to $30 \mathrm{~min}$, but the values decreased when the extraction time reached $40 \mathrm{~min}^{[34]}$. In a study about optimizing a method for green tea extraction by Das and Eun, it was reported that the TPC values of aqueous green tea UE and AG extracts increased from $15 \mathrm{~min}$ to $30 \mathrm{~min}$ at $60^{\circ}$. In contrast to the present study, they found that the AE technique was more effective than the $\mathrm{UE}$ at $60^{\circ}$, in 5 to $30 \mathrm{~min}$ extraction time ${ }^{[17]}$.

Finally, TPC, ABTS, DPPH and FRAP values obtained from the UE method were superior to the AE method extracts. Applying the combination of $60 \mathrm{~min}$ of 
extraction time, $60^{\circ}$ of extraction temperature and $70 \%$ methanol ratio was seen to be the most effective (optimum) parameters for the phenolic content and antioxidant activity of $M$. prolifera, by UE method.

With the purpose of identifying the active phenolic compounds present in M. prolifera, the HPLC-DAD system was used with a validated method previously reported by Burnaz et al. (Table 1) ${ }^{[31]}$. Fig. 2A and
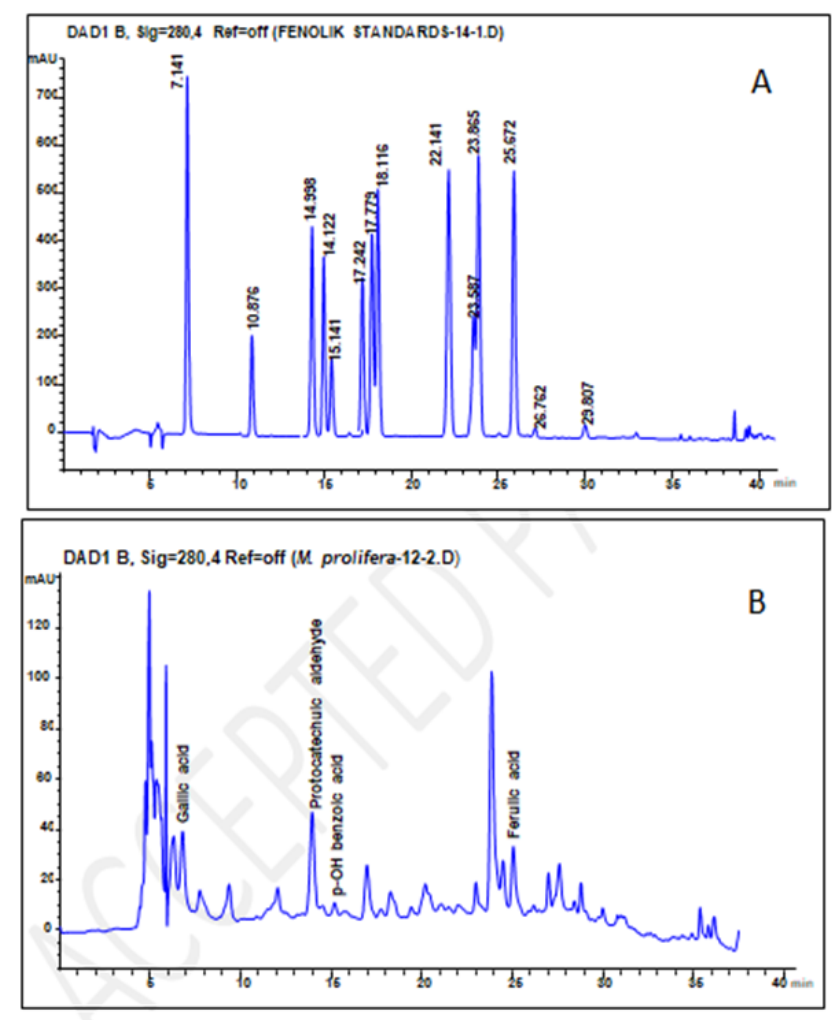

Fig. 2: HPLC chromatograms of (A) phenolic standards and (B) M. prolifera extract at $280 \mathrm{~nm}$ fig. 2B shows the chromatograms of the mixture of (A) standard phenolic acids and (B) M. prolifera extract at $280 \mathrm{~nm}$. The chromatogram of sample number 12 (UE method, $70 \%$ methanol, $60^{\circ}, 60 \mathrm{~min}$ ) with the highest phenolic content and antioxidant activity was selected as representative and shown in fig. 2 . The approximate RTs of all phenolic compounds and the peak areas of found phenolics in this sample are given in Table 4. The peaks identified on chromatogram $\mathrm{B}$ are gallic acid (6.997), protocatechuic aldehyde, (14.018), p-OH benzoic acid (14.990) and ferulic acid (25.232). Protocatechuic aldehyde was the dominant studied phenolic compound in $M$. prolifera extract (in $70 \%$ methanol) that accounted for $4.86 \%$ of the total extracted compounds. Besides, the unknown peaks at RT of 4.979 and 23.886 are valuable, which account for $12.27 \%$ and $8.49 \%$ of the total extracted compounds, respectively.

This is the first report on the phenolic compounds and antioxidant activities of $M$. prolifera. Further studies on other bioactivities (antimicrobial, anticancer, etc.) could be especially interesting because it has high polyphenolic potential and significant antioxidant activity. Protocatechualdehyde, gallic acid, p-OH benzoic acid and ferulic acid were identified by using the HPLC-DAD system. There were also unidentified significant compounds that should be studied in detail. Also, it is recommended that other Mammillaria species have examined for their bioactivities. Besides, the application of ultrasonication increases both polyphenol content and antioxidant activity from the $M$. prolifera extracts. Moreover, the ultrasonic application is more effective and low-cost technology for determining

TABLE 4: MAJOR PHENOLIC COMPOUNDS IDENTIFIED IN $M$. prolifera EXTRACT BY HPLC-DAD SYSTEM AT $280 \mathrm{~nm}$

\begin{tabular}{|c|c|c|c|c|}
\hline Compounds & $\begin{array}{c}\text { Approximate } \mathrm{RT}^{*} \\
(\mathrm{~min})\end{array}$ & $\begin{array}{c}\text { Area } \\
\left(\mathrm{mAU}{ }^{*} \min \right)\end{array}$ & $\begin{array}{c}\text { Peak area } \\
(\%) \\
\end{array}$ & $\begin{array}{c}\text { Maximum } \\
\text { wavelength }\left(\lambda_{\max }\right)\end{array}$ \\
\hline Gallic acid & 7.141 & 587.2 & 3.2 & 274 \\
\hline Protocatechuic acid & 10.876 & nd & nd & 260 \\
\hline Protocatechuic aldehyde & 14.122 & 884.9 & 4.9 & 280 \\
\hline p-OH benzoic acid & 14.998 & 87.3 & 0.5 & 260 \\
\hline Chlorogenic acid & 15.141 & nd & nd & 324 \\
\hline Vanillic acid & 17.242 & nd & nd & 260 \\
\hline Caffeic acid & 17.779 & nd & nd & 324 \\
\hline Syringic acid & 18.116 & nd & nd & 274 \\
\hline Vanillin & 22.141 & nd & nd & 280 \\
\hline p-Coumaric acid & 23.587 & nd & nd & 308 \\
\hline Syringic aldehyde & 23.865 & nd & nd & 308 \\
\hline Ferulic acid & 25.672 & 23.9 & 2.3 & 324 \\
\hline Sinapic acid & 26.762 & nd & nd & 324 \\
\hline Benzoic acid & 29.807 & nd & nd & 240 \\
\hline
\end{tabular}

Note: *RT: retention time; nd: Not detected in the samples; mAU: milli absorbance unit 
the phenolic content and antioxidant activity of M. prolifera extracts as it requires shorter extraction time and lower temperature compared to the other extraction methods. Finally, the combination of $60 \mathrm{~min}$ of extraction time, extraction temperature of $60^{\circ}$ and $70 \%$ methanol ratio with the UE method seems to be more effective parameters for achieving optimum antioxidant capacity in $M$. prolifera extract. These results suggest that $M$. prolifera plant possesses antioxidant properties and could be used as an alternative natural antioxidant source, after toxicological examinations.

\section{Acknowledgements:}

The author thank Murat Kucuk (Professor at Karadeniz Technical University) and Huri Ilyasoglu (Associate Professor at Gumushane University) for proof reading the article.

\section{Conflicts of interest:}

The authors declared no conflict of interest.

\section{REFERENCES}

1. Talemi EP, Sedaghathoor S. A study on biochemical properties of different parts of three Opuntia species (Opuntia ficusindica, O. microdasys, and O. basilaris). J Prof Assoc Cactus Dev 2017;19:32-44.

2. Ramirez-Malagon R, Aguilar-Ramirez I, Borodanenko A, Perez-Moreno L, Barrera-Guerra JL, Nunez-Palenius HG, et al. In vitro propagation of ten threatened species of Mammillaria (Cactaceae). In Vitro Cell Dev Biol Plant 2007;43(6):660-5.

3. Ammar I, Ennouri M, Attia H. Phenolic content and antioxidant activity of cactus (Opuntia ficus-indica L.) flowers are modified according to the extraction method. Ind Crops Prod 2015;64:97-104.

4. Buxbaum F. The phylogenetic division of the subfamily Cereoideae, Cactaceae. Madrono 1958;14(6):177-206.

5. Ramirez-Malagon R, Aguilar-Ramirez I, Borodanenko A, Perez-Moreno L, Barrera-Guerra JL, Nuñez-Palenius HG, et al. Preface. Southwest Nat 2004;41(7):1086-98.

6. Ortega-Baes P, Suhring S, Sajama J, Sotola E, Alonso-Pedano $\mathrm{M}$, Bravo $\mathrm{S}$, et al. Diversity and conservation in the cactus family. In: Desert plants. Springer, Berlin: Heidelberg; 2010. p. $157-73$.

7. Akyuz E, Sahin H, Islamoglu F, Kolayli S, Sandra P. Evaluation of phenolic compounds in Tilia rubra subsp. caucasica by HPLC-UV and HPLC-UV-MS/MS. Int J Food Prop 2014;17(2):331-43.

8. Shetty AA, Rana MK, Preetham SP. Cactus: a medicinal food. J Food Sci Technol 2012;49(5):530-6.

9. Johnson MA. Diploid cytotypes in Mammillaria prolifera and three other Mammillaria species. Cact Succ J Gr Brit 1978;40(1):9-12.

10. Nazareno MA. Phytochemicals of nutraceutical importance from cactus and their role in human health. In: Prakash D, Sharma G, editors. Phytochemicals of nutraceutical importance. CAB International; 2014. p. 103.

11. Alimi H, Hfaiedh N, Bouoni Z, Sakly M, Rhouma KB.
Evaluation of antioxidant and antiulcerogenic activities of Opuntia ficus indica f. inermis flowers extract in rats. Environ Toxicol Pharmacol 2011;32(3):406-16.

12. Sim KS, Nurestri AS, Norhanom AW. Phenolic content and antioxidant activity of Pereskia grandifolia Haw. (Cactaceae) extracts. Pharmacogn Mag 2010;6(23):248-54.

13. Talemi EP, Sedaghathoor S. A study on biochemical properties of different parts of three Opuntia species (Opuntia ficusindica, O. microdasys, and O. basilaris). J Prof Assoc Cactus Dev 2017;19:32-44.

14. Hifney AF, Fawzy MA, Abdel-Gawad KM, Gomaa M. Industrial optimization of fucoidan extraction from Sargassum sp. and its potential antioxidant and emulsifying activities. Food Hydrocoll 2016;54:77-88.

15. Rojas MC, Brewer MS. Effect of natural antioxidants on oxidative stability of frozen, vacuum-packaged beef and pork. J Food Qual 2008;31(2):173-88.

16. Karacelik AA, Kucuk M, Iskefiyeli Z, Aydemir S, De Smet S, Miserez B, et al. Antioxidant components of Viburnum opulus L. determined by on-line HPLC-UV-ABTS radical scavenging and LC-UV-ESI-MS methods. Food Chem 2015;175:106-14.

17. Das PR, Eun JB. A comparative study of ultra-sonication and agitation extraction techniques on bioactive metabolites of green tea extract. Food Chem 2018;253:22-9.

18. Kaufmann B, Christen P. Recent extraction techniques for natural products: microwave-assisted extraction and pressurized solvent extraction. Phytochem Anal 2002;13(2):105-13.

19. Khan MK, Abert-Vian M, Fabiano-Tixier AS, Dangles O, Chemat F. Ultrasound-assisted extraction of polyphenols (flavanone glycosides) from orange (Citrus sinensis L.) peel. Food Chem 2010;119(2):851-8.

20. Wang L, Weller CL. Recent advances in extraction of nutraceuticals from plants. Trends Food Sci Technol 2006;17(6):300-12.

21. Wu CH, Murthy HN, Hahn EJ, Lee HL, Paek KY. Efficient extraction of caffeic acid derivatives from adventitious roots of Echinacea purpurea. Czech J Food Sci 2008;26:254-8.

22. Espada-Bellido E, Ferreiro-Gonzalez M, Carrera C, Palma M, Barroso CG, Barbero GF. Optimization of the ultrasoundassisted extraction of anthocyanins and total phenolic compounds in mulberry (Morus nigra) pulp. Food Chem 2017;219:23-32.

23. Tsai YL, Chiou SY, Chan KC, Sung JM, Lin SD. Caffeic acid derivatives, total phenols, antioxidant and antimutagenic activities of Echinacea purpurea flower extracts. LWT Food Sci Technol 2012;46(1):169-76.

24. Pellati F, Benvenuti S, Magro L, Melegari M, Soragni F. Analysis of phenolic compounds and radical scavenging activity of Echinacea spp. J Pharm Biomed Anal 2004;35(2):289-301.

25. Pinelo M, Rubilar M, Jerez M, Sineiro J, Nunez MJ. Effect of solvent, temperature, and solvent-to-solid ratio on the total phenolic content and antiradical activity of extracts from different components of grape pomace. J Agric Food Chem 2005;53(6):2111-7.

26. Singleton VL, Rossi JA. Colorimetry of total phenolics with phosphomolybdic-phosphotungstic acid reagents. Am J Enol Vitic 1965;16(3):144-58.

27. Re R, Pellegrini N, Proteggente A, Pannala A, Yang M, RiceEvans C. Antioxidant activity applying an improved ABTS radical cation decolorization assay. Free Radic Biol Med 1999;26(9-10):1231-7.

28. Brand-Williams W, Cuvelier ME, Berset CL. Use of a free radical method to evaluate antioxidant activity. LWT Food Sci 
Technol 1995;28(1):25-30.

29. Benzie IF, Strain JJ. [2] Ferric reducing/antioxidant power assay: direct measure of total antioxidant activity of biological fluids and modified version for simultaneous measurement of total antioxidant power and ascorbic acid concentration. Methods Enzymol 1999;299:15-27.

30. Kucuk M, Kolaylı S, Karaoglu S, Ulusoy E, Baltacı C, Candan F. Biological activities and chemical composition of three honeys of different types from Anatolia. Food Chem 2007;100(2):526-34.

31. Burnaz NA, Kucuk M, Akar Z. An on-line HPLC system for detection of antioxidant compounds in some plant extracts by comparing three different methods. J Chromatogr B 2017;1052:66-72.

32. Musa KH, Abdullah A, Jusoh K, Subramaniam V. Antioxidant activity of pink-flesh guava (Psidium guajava L.): effect of extraction techniques and solvents. Food Anal Methods 2011;4(1):100-7.

33. Keskin S, Keskin M, Kolayli S. Ultrasound assisted extraction of pectin from Trachystemon orientalis L. J Med Herbs Ethnomed 2019;9(5):16-9.

34. Teh SS, Birch EJ. Effect of ultrasonic treatment on the polyphenol content and antioxidant capacity of extract from defatted hemp, flax and canola seed cakes. Ultrason Sonochem 2014;21(1):346-53.

35. Jacques RA, dos Santos Freitas L, Perez VF, Dariva C, de Oliveira AP, de Oliveira JV, et al. The use of ultrasound in the extraction of Ilex paraguariensis leaves: a comparison with maceration. Ultrason Sonochem 2007;14(1):6-12.

36. J Mason T, Chemat F, Vinatoru M. The extraction of natural products using ultrasound or microwaves. Curr Org Chem 2011;15(2):237-47.

37. Rezende YR, Nogueira JP, Narain N. Comparison and optimization of conventional and ultrasound assisted extraction for bioactive compounds and antioxidant activity from agroindustrial acerola (Malpighia emarginata DC) residue. LWT Food Sci Technol 2017;85:158-69.

38. Tabaraki R, Nateghi A. Optimization of ultrasonic-assisted extraction of natural antioxidants from rice bran using response surface methodology. Ultrason Sonochem 2011;18(6):1279-
86.

39. Anwar F, Przybylski R. Effect of solvents extraction on total phenolics and antioxidant activity of extracts from flaxseed (Linum usitatissimum L.). Acta Sci Pol Technol Aliment 2012;11(3):293-302.

40. Turkmen N, Sari F, Velioglu YS. Effects of extraction solvents on concentration and antioxidant activity of black and black mate tea polyphenols determined by ferrous tartrate and FolinCiocalteu methods. Food Chem 2006;99(4):835-41.

41. Do QD, Angkawijaya AE, Tran-Nguyen PL, Huynh LH, Soetaredjo FE, Ismadji S, et al. Effect of extraction solvent on total phenol content, total flavonoid content and antioxidant activity of Limnophila aromatica. J Food Drug Anal 2014;22(3):296-302.

42. Mokrani A, Madani K. Effect of solvent, time and temperature on the extraction of phenolic compounds and antioxidant capacity of peach (Prunus persica L.) fruit. Sep Purif Technol 2016;162:68-76.

43. Liyana-Pathirana C, Shahidi F. Optimization of extraction of phenolic compounds from wheat using response surface methodology. Food Chem 2005;93(1):47-56.

44. Rodrigues S, Pinto GA, Fernandes FA. Optimization of ultrasound extraction of phenolic compounds from coconut (Cocos nucifera) shell powder by response surface methodology. Ultrason Sonochem 2008;15(1):95-100.

45. Chan SW, Lee CY, Yap CF, Wan Aida WM, Ho CW. Optimisation of extraction conditions for phenolic compounds from limau purut (Citrus hystrix) peels. Int Food Res J 2009; 16(2):203-13.

46. Vuong QV, Golding JB, Stathopoulos CE, Nguyen MH, Roach PD. Optimizing conditions for the extraction of catechins from green tea using hot water. J Sep Sci 2011;34(21):3099-106.

47. Spigno G, Tramelli L, De Faveri DM. Effects of extraction time, temperature and solvent on concentration and antioxidant activity of grape marc phenolics. J Food Eng 2007;81(1) :200-8.

48. Cacace JE, Mazza G. Extraction of anthocyanins and other phenolics from black currants with sulfured water. J Agric Food Chem 2002;50(21):5939-46. 